\title{
Full validation of an electrothermal atomic absorption assay for zinc in hepatic tissue using a fast sample preparation procedure
}

\author{
Pedro Eduardo Fröehlich ${ }^{\mathrm{c}, *}$, Raquel Borges Pinto ${ }^{\mathrm{a}}$, André Castagna Wortmann ${ }^{\mathrm{a}}$, \\ Richard Borba Magalhães ${ }^{a}$, Ana Cláudia Reis Schneider ${ }^{b}$, Jéferson José Ferreira ${ }^{\mathrm{c}}$ and \\ Themis Reverbel da Silveira ${ }^{a, b}$ \\ a Programa de Pós-Graduação em Gastroenterologia, Faculdade Medicina, Universidade Federal do \\ Rio Grande do Sul, Porto Alegre, Brasil \\ ${ }^{\mathrm{b}}$ Programa de Pós-Graduação em Pediatria, Faculdade Medicina, Universidade Federal do Rio \\ Grande do Sul, Porto Alegre, Brasil \\ ${ }^{\mathrm{c}}$ Programa de Pós-Graduação em Ciências Farmacêuticas, Faculdade de Farmácia, Universidade \\ Federal do Rio Grande do Sul, Porto Alegre, Brasil
}

\begin{abstract}
The objective of this work was to develop and fully validate an analytical assay to quantify zinc in hepatic tissue. The procedure should be as simple and fast as possible in order to avoid sample contamination. The amount of sample used should also reflect the sample size usually obtained in clinical biopsies, which are about 3-4 mg at most. The validation protocol is in accordance to international guidelines, such as ICH and FDA. The parameters evaluated were precision, accuracy, range, limit of detection and limit of quantification. The method was evaluated in the 2.0-32.0 parts per billion $(\mu \mathrm{g} / \mathrm{l})$ range. Under the described conditions intra and inter day precision of the three levels of quality controls were lower than 9.06 and 5.27, respectively, expressed as relative standard deviation (RSD). The accuracy ranged from 86.35 to $114.71 \%$. Limit of detection and limit of quantification were 0.60 and $2.0 \mu \mathrm{g} / \mathrm{l}$, respectively. Fresh bovine liver samples were used in order to evaluate the clinical procedure used to collect biopsies. According to the results and experimental protocol, the method is fully validated and ready to use in clinical trials involving zinc quantitation using hepatic samples as small as $2.00 \mathrm{mg}$ of dry tissue.
\end{abstract}

Keywords: Hepatic tissue, zinc, atomic absorption, validation

\section{Introduction}

The knowledge of hepatic physiological changes that occur in children and teenagers demanded the development of very specific and sensitive analytical procedures [1]. Before the era of liver transplantation children with hepatic chronic disease were condemned to live only a few years and with no quality. Hepatic transplant brought some hope to this situation. However it is still a very complex procedure, and nutrition related factors are a very important aspect involved in its success [1-3].

\footnotetext{
${ }^{*}$ Corresponding author: Pedro E. Fröehlich, Faculdade de Farmácia, Universidade Federal do Rio Grande do Sul, Av. Ipiranga, 2752/703, CEP 90610-000, Porto Alegre, RS, Brazil. Tel.: +55 513316 5313; Fax: +55 513316 5437; E-mail: pedroef@farmacia.ufrgs.br.
} 
Zinc is part of several enzymatic systems as a component in metalloenzymes or as an enzymatic cofactor in more than 300 metabolic processes [4]. It is part of carbonic anhydrase, which is present in the erythrocytes. This enzyme is responsible for the fast combination of water and carbon dioxide in the peripheral capillaries and for the fast release of carbon dioxide in the lungs [5,6].

The assessment of zinc concentration in the whole blood, plasma or hepatic tissue is useful to evaluate if there is zinc deficiency as well as the severity of the situation. Most of the methods available are not very sensitive to diagnose a small zinc deficiency [6].

Atomic absorption spectroscopy is the most used technique to quantify zinc in the body. Plasma and urinary levels of this metal range from $50-150 \mu \mathrm{g} / \mathrm{dl}$ while in hepatic tissue the normal level is about $100 \mu \mathrm{g} / \mathrm{g}$ of dry tissue. In the present work an assay using graphite furnace was developed in order to allow an accurate and precise determination of zinc in a small amount of hepatic tissue sample that reflects the sample size usually available in liver biopsies. Although several methods have been described in the literature over the years, most of them do not comply with validation requirements and involve some time demanding sample preparation [7-10].

\section{Material and methods}

\subsection{Instrumentation}

The analytical procedure was carried out using an AAnalist-300 model atomic absorption spectrophotometer with deuterium-arc background correction equipped with a HGA-800 graphite furnace and an AS-70 auto sampler, all from Perkin-Elmer (Welleslay, MA, USA). The emission source was a single element (Zn) hollow cathode lamp, and pyrolitic graphite-coated tubes with L'vov platforms, all from Perkin-Elmer. The purge gas was argon. For sample digestion, a sonicator and an oven were used. Fresh bovine liver samples were lyophilized (Micro Moduli 97, BOC Edwards, Wilmington, MA, USA) to constant weight before digestion.

\subsection{Reagents}

Standard zinc solutions were prepared from a $1 \mathrm{~g} / \mathrm{l}$ stock solution (Titrisol, Merck, Germany). Bovine liver standard from the National Institute of Standards and Technology-NIST (Batch 1577b, Gaithersburg, MD, USA) was used to prepare the quality controls. Fresh bovine liver to simulate the biopsy process was acquired in a local market. Water used in the whole procedure was Milli-Q ${ }^{\circledR}$ (Millipore, USA) and nitric acid (analytical grade, Merck, Germany) was distilled twice in a custom made glass apparatus. Triton X-100 was also from Merck. All glassware and plastic sample vials and pipette tips were decontaminated with $10 \%$ nitric acid solution (immersed for 4 hours), rinsed thoroughly with water and let over a plastic tray in an oven at $60^{\circ} \mathrm{C}$ to dry. The surgical material was also washed with nitric acid and water prior to sterilization. After that, all the materials were protected in decontaminated plastic bags until they were used.

\subsection{Calibration curve and quality controls}

Solvent solution: a mixture of water, Triton X-100 (0.5\% v/v) and nitric acid (1\% v/v) was used to dilute the calibration curve solutions as well as samples. 
Calibration curve: dilutions were made from Titrisol solution in order to obtain final zinc concentrations of 2.0, 4.0, 8.0, 16.0, and $32.0 \mu \mathrm{g} / 1$. These dilutions were prepared fresh daily.

Quality control samples: an amount of NIST bovine liver (2.00-4.00 mg) was accurately weighted directly in a $2 \mathrm{ml}$ Eppendorf tube and $500 \mu \mathrm{l}$ of concentrated nitric acid was added. The tubes were closed and sonicated for 30 minutes and then transferred into an oven at $60^{\circ} \mathrm{C}$ for 1 hour. Three aliquots of each sample were transferred to volumetric flasks and diluted to produce solutions containing about 6.0, 15.0 and $25.0 \mu \mathrm{g} / \mathrm{l}$ of zinc.

Fresh bovine liver samples: 28 fragments similar in size with real biopsy samples were obtained with the same procedure used in human patients. All fragments were removed from the same liver and close to each other in order to verify the reproducibility of the procedure. After extraction, each fragment was transferred to a previously weighted Eppendorf tube and freeze-dried to constant weight. After this procedure fragments were processed as described above for the NIST samples and diluted to produce a solution containing about $20.0 \mu \mathrm{g} / \mathrm{l}$ of zinc.

\subsection{Validation protocol}

Method validation was conducted according to published guidelines [11,12]. For the construction of each calibration curve (concentration versus peak area of standard) five different zinc concentrations were analyzed in triplicate. The following parameters were evaluated: specificity, linearity/range, inter and intra-day precision, accuracy, limit of detection (LOD) and limit of quantitation (LOQ).

Linearity of three calibration curves was tested by ANOVA and linear regression analysis. Assay performance was evaluated by intra-day and inter-day precision, determined from quality control samples in three different concentrations ( $n=6$ for each concentration in the first day and $n=3$ in the second and third day). Accuracy of method was evaluated comparing the results of the quality control samples obtained in the first day $(n=6)$ with the result stated in the NIST Certificate of Analysis and considering the sample sizes and the dilutions made. The precision and accuracy are expressed in terms of relative standard deviations (RSD). The interference of the matrix was investigated by comparing the calibration curve with quality control results. The matrix is considered not to interfere with the analysis if the areas of quality controls fit well in the linear regression curve of standards and the peaks have similar shapes. Limit of detection was determined as the concentration that gave a peak three times higher than the average noise height and limit of quantification was considered as being 3.3 times this concentration.

\subsection{Instrumental conditions}

The spectrophotometer settings used are listed in Table 1.

Table 1

Instrument settings

\begin{tabular}{lc}
\hline wavelength $(\mathrm{nm})$ & 213.9 \\
slit width $(\mathrm{nm})$ & 0.20 \\
lamp current $(\mathrm{mA})$ & 15 \\
background correction (deuterium lamp) & on \\
sample volume $(\mu \mathrm{l})$ & 10 \\
\hline
\end{tabular}




\section{Results and discussion}

\subsection{Choice of the heating programme}

The furnace programme conditions are given in Table 2. Conditions for the drying stage were set in two steps to achieve complete drying of the samples without boiling. Ashing time was a little longer than standard conditions to improve the results. Before atomization an extra step was added, bringing down the temperature to $30^{\circ} \mathrm{C}$. This step improved the shape of the absorbance peak. Every step was carefully optimized based on observation of the area under the absorbance versus time peak as well as its shape and the reproducibility of the results. Figure 1 shows a peak obtained using the final conditions described.

\subsection{Linearity/range}

Atomic absorption does not always produce a linear response over a wide concentration range. A nonlinear equation was used to fit the data. The average non-linear coefficient of correlation for seven calibration curves was 0.994 . Figure 2 shows the average calibration curve. Therefore the calibration curve was proportional in the 2.0 to $32.0 \mu \mathrm{g} / \mathrm{l}$ range.

Table 2

Furnace conditions used in the determination of zinc in hepatic tissue

\begin{tabular}{lrrcc}
\hline Step & $\begin{array}{r}\text { Temp. } \\
\left({ }^{\circ} \mathrm{C}\right)\end{array}$ & $\begin{array}{r}\text { Ramp time } \\
(\mathrm{s})\end{array}$ & $\begin{array}{c}\text { Hold time } \\
(\mathrm{s})\end{array}$ & $\begin{array}{c}\text { Argon flow-rate } \\
(\mathrm{ml.min}\end{array}$ \\
\hline drying & 120 & 20 & 20 & 30 \\
ashing & 700 & 5 & 30 & 30 \\
pre-atomization & 30 & 5 & 15 & 30 \\
atomization & 1800 & 0 & 4 & 0 \\
cleaning & 2200 & 1 & 5 & 30 \\
\hline
\end{tabular}

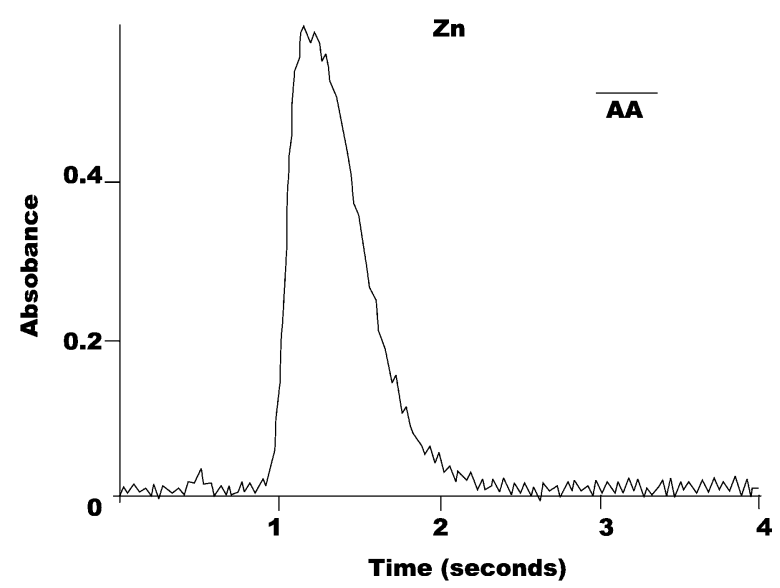

Fig. 1. Absorption curve for zinc using electrothermal atomization (standard solution containing $4 \mu \mathrm{g} / \mathrm{l}$ of zinc). 


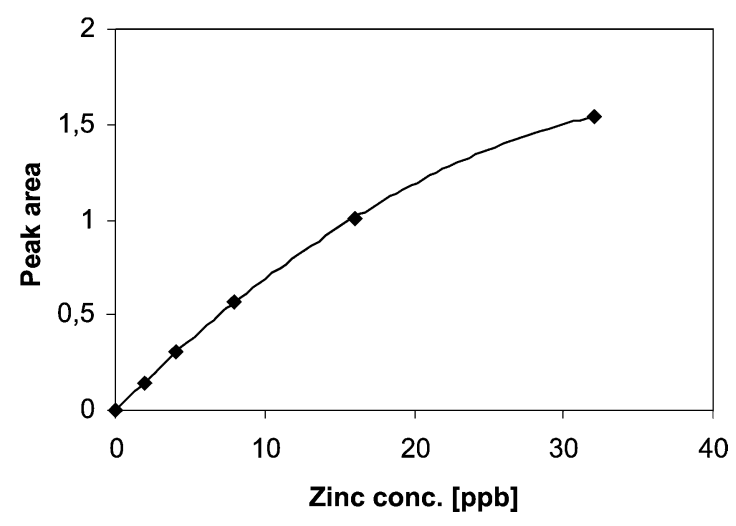

Fig. 2. Typical calibration curve for zinc $(2.0-32.0 \mu \mathrm{g} / \mathrm{l})$.

\subsection{Precision/accuracy}

A summary of the results for three concentrations of quality controls is shown in Table 3. Intraday precision ranged from 4.2 to 13.7 (RSD) for the three concentration evaluated. Inter-day precision was even better, ranging from 2.0 to 4.5 (RSD). These results are all in accordance with international guidelines that allow a maximum value of $15 \%$, expressed as RSD. Considering the six samples analyzed in the first day, accuracy ranged from 86.7 to 114.7 , also inside the acceptable value of $15 \%$.

\subsection{Limit of detection/Limit of quantification}

Based on a signal to noise ratio, measured after printing the peak obtained for the $2.0 \mu \mathrm{g} / \mathrm{l}$ sample, limit of detection was considered as being $0.6 \mu \mathrm{g} / \mathrm{l}$ and limit of quantitation as being $2.0 \mu \mathrm{g} / \mathrm{l}$.

\subsection{Fresh bovine liver samples}

Table 4 shows the average results for the analysis of 28 fragments of bovine liver were extracted using the same surgical procedure and instrumentation used for removal of human liver biopsies, in order to verify possible contamination of samples. Fresh liver samples were freeze dried to constant weight and digested as described earlier. Only the RSD of the results was evaluated, since no information was available for the real zinc concentration of that particular sample. A calibration curve and five quality controls prepared with similar amounts of NIST standard were used in the analytical run. The results are shown in Table 4. The concentration of zinc in NIST standard was $136.3 \pm 9.7 \mu \mathrm{g} / \mathrm{g}$ of dry tissue and the result for biopsies samples was $182.5 \pm 13.1 \mu \mathrm{g} / \mathrm{g}$ dry tissue, showing that the procedure was precise and did not interfere with the analysis. Considering that the zinc content in the liver samples are in good agreement with previously reported values for bovine liver tissue $[13,14]$ and values ranging from $100-338 \mu \mathrm{g} / \mathrm{g}$ have been reported in the literature for humans [15-17], the overall method conditions seem to be adequate for analysis of zinc on human biopsy size samples. 
Table 3

Summary of quality control results

\begin{tabular}{|c|c|c|c|c|c|c|c|}
\hline Day & Sample ID & $\begin{array}{l}\text { Weight } \\
\text { (mg) }\end{array}$ & $\begin{array}{l}\text { Theoretical* } \\
\text { conc. }(\mu \mathrm{g} / \mathrm{l})\end{array}$ & $\begin{array}{c}\text { Practical } \\
\text { conc. }(\mu \mathrm{g} / \mathrm{l})\end{array}$ & $\%$ & $\begin{array}{c}\text { Average } \\
\%\end{array}$ & $\begin{array}{c}\mathrm{RSD} \\
\%\end{array}$ \\
\hline \multirow[t]{18}{*}{1} & \multirow[t]{3}{*}{ A } & \multirow[t]{3}{*}{3.98} & 6.07 & 5.55 & 91.5 & & \\
\hline & & & 15.16 & 14.53 & 95.8 & & \\
\hline & & & 25.27 & 28.99 & 114.7 & & \\
\hline & \multirow[t]{3}{*}{$\mathrm{B}$} & \multirow[t]{3}{*}{3.36} & 5.12 & 5.10 & 99.6 & Low QC & \\
\hline & & & 12.80 & 11.10 & 86.7 & 95.6 & 4.8 \\
\hline & & & 21.34 & 19.09 & 89.5 & & \\
\hline & \multirow[t]{3}{*}{$\mathrm{C}$} & \multirow[t]{3}{*}{3.46} & 5.27 & 4.72 & 89.5 & & \\
\hline & & & 13.18 & 14.33 & 108.7 & & \\
\hline & & & 21.97 & 23.92 & 108.9 & Mid QC & \\
\hline & \multirow[t]{3}{*}{$\mathrm{D}$} & \multirow[t]{3}{*}{3.58} & 5.46 & 5.45 & 99.9 & 103.3 & 9.8 \\
\hline & & & 13.64 & 14.75 & 108.1 & & \\
\hline & & & 22.73 & 22.77 & 104.6 & & \\
\hline & \multirow[t]{3}{*}{$\mathrm{E}$} & \multirow[t]{3}{*}{3.76} & 5.73 & 5.69 & 99.3 & & \\
\hline & & & 14.33 & 15.25 & 106.5 & High QC & \\
\hline & & & 23.88 & 22.31 & 93.4 & 103.8 & 9.8 \\
\hline & \multirow[t]{3}{*}{$\mathrm{F}$} & \multirow[t]{3}{*}{3.23} & 4.92 & 4.63 & 94.1 & & \\
\hline & & & 12.31 & 14.03 & 114.0 & & \\
\hline & & & 20.51 & 22.89 & 111.6 & & \\
\hline \multirow[t]{9}{*}{2} & \multirow[t]{3}{*}{ G } & \multirow[t]{3}{*}{4.07} & 6.20 & 5.48 & 88.4 & & \\
\hline & & & 15.51 & 16.78 & 108.2 & Low QC & \\
\hline & & & 25.84 & 25.25 & 97.7 & 96.9 & 7.7 \\
\hline & \multirow[t]{3}{*}{$\mathrm{H}$} & \multirow[t]{3}{*}{3.51} & 5.35 & 5.35 & 100.0 & & \\
\hline & & & 13.37 & 12.05 & 90.1 & Mid QC & \\
\hline & & & 22.29 & 20.84 & 93.5 & 96.6 & 10.4 \\
\hline & \multirow[t]{3}{*}{ I } & \multirow[t]{3}{*}{3.78} & 5.76 & 5.89 & 102.2 & & \\
\hline & & & 14.40 & 13.17 & 91.5 & High QC & \\
\hline & & & 24.00 & 21.55 & 89.8 & 93.6 & 4.2 \\
\hline \multirow[t]{9}{*}{3} & \multirow[t]{3}{*}{$\mathrm{J}$} & \multirow[t]{3}{*}{2.99} & 4.56 & 5.05 & 110.4 & & \\
\hline & & & 11.39 & 10.53 & 92.4 & Low QC & \\
\hline & & & 18.99 & 21.46 & 113.1 & 100.2 & 10.8 \\
\hline & \multirow[t]{3}{*}{ K } & \multirow[t]{3}{*}{3.81} & 5.81 & 5.16 & 88.9 & & \\
\hline & & & 14.52 & 13.27 & 91.42 & Mid QC & \\
\hline & & & 24.19 & 20.89 & 86.4 & 96.8 & 8.8 \\
\hline & \multirow[t]{3}{*}{$\mathrm{L}$} & \multirow[t]{3}{*}{3.04} & 4.63 & 4.69 & 101.2 & & \\
\hline & & & 11.58 & 12.35 & 106.6 & High QC & \\
\hline & & & 19.30 & 18.72 & 99.67 & 98.8 & 13.7 \\
\hline
\end{tabular}

* After digestion, three aliquots of each sample were diluted to provide solutions containing approximately 6.00 (Low), 15.00 (Mid) and 25.0 (High) $\mu \mathrm{g} / \mathrm{l}$.

Table 4

Fresh bovine liver samples analyzed using the validated method

\begin{tabular}{lc}
\hline & Results (average \pm RSD) \\
\hline Quality controls $^{*}$ & $136.3 \pm 9.7 \mathrm{mg} / \mathrm{g}$ dry tissue \\
Biopsies samples $^{* *}$ & $182.5 \pm 13.1 \mathrm{mg} / \mathrm{g}$ dry tissue \\
\hline${ }^{*} n=5,{ }^{* *} n=28$. &
\end{tabular}




\section{Conclusion}

The present work details a full validation method for zinc quantitation in hepatic tissue that will be useful as an important tool to access information on zinc status in patients. The sample preparation is quite simple and the calibration curve was prepared with standard zinc solution, with no addition of sample modifiers and also showed no interference of the biological matrix. The results are in agreement with international guidelines and precision and accuracy inside the allowed $15 \%$ range was achieved in the 2.0 to $32.0 \mathrm{ng} / \mathrm{ml}$ concentration interval, using samples as small as $2.00 \mathrm{mg}$ that reflect the usual amount of dry tissue obtained in the liver biopsy procedure.

\section{References}

[1] W.F. Balistreri, Pediatric hepatology: a half century of progress, Clin. Liver Dis. 4 (2000), 191-210.

[2] R.M. Ghobrial, F. Amersi, S.V. McDiarmid and R.W. Busuttil, Pediatric liver transplantation, in: Transplantation of the Liver, 3rd. edn, W.C. Maddrey, E.R. Schiff and M.F. Sorrell eds, Lips \& Wilkins, Philadelphia, 2001, pp. 79-99.

[3] L. Endre, F.W.J. Beck and A.S. Prasad, The role of zinc in human health, J. Elem. Exper. Med. 3 (1990), $337-375$.

[4] L. Rink and H. Kirchner, Zinc-altered function and cytokine production, J. Nutr. 130 (2000), 1407s-1411s.

[5] B.L. O'Dell, Role of zinc in plasma membrane function, J. Nutr. 130 (2000), 1432s-1436s.

[6] S. Klein and K.N. Jeejeebhoy, The malnourished patient: nutritional assessment and management, in: Gastrointestinal and Liver Disease: Pathophysiology, Diagnosis, Management, M. Feldman, L.S. Friedman and M.H. Sleisenger, eds, 7th edn, Saunders, Philadelphia, 2002, pp. 265-286.

[7] K.M. Hambidge, Plasma and urine zinc in infants and children with extrahepatic biliary atresia, J. Pediatr. Gastroenterol. Nutr. 6 (1987), 872-877.

[8] L. Capocaccia, M. Merli, C. Piat et al., Zinc and other trace elements in liver cirrhosis, Ital, J. Gastroenterol. 23 (1991), 386-391.

[9] M.M. Brzoska, J. Moniuszko-Jakoniuk, M. Jurczuk, M. Galazyn-Sidorczuk and K.H. Brown, Effect of infections on plasma zinc concentration and implications for zinc status in low-income countries, Am. J. Clin. Nutr. 68 (1998), 425s429 s.

[10] R.D. Beaty and J.D. Kerber, Concepts, Instrumentation and Techniques in Atomic Absoption Spectrophotometry, The Perkin-Elmer Corporation, Wellesley, 1993, pp.1-8.

[11] ICH Harmonised Tripartite Guideline. Validation of analytical procedures: methodology. Q2B, in: International Conference on Harmonisation of Technical Requirements for Registration of Pharmaceuticals for Human Use, 1996, pp. 1-13.

[12] V.P. Shah, K.K. Midha, J.W. Findlay, H.M. Hill, J.D. Hulse, I.J. McGilveray, G. McKay, K.J. Miller, R.N. Patnaik, M.L. Powell, A. Tonelli, C.T. Viswanathan and A. Yacobi, Bioanalytical method validation: a revisit with a decade of progress, Pharm. Res. 17 (2000), 1551-1557.

[13] T.S. Koh, T.H. Benson and G.J. Judson, Trace element analysis of bovine liver: interlaboratory survey in Australia and New Zealand, Journal of the Association of Official Analytical Chemists 63 (1980), 809-813.

[14] C.L. Wright and J.W. Spears, Effect of zinc source and dietary level on zinc metabolism in Holstein calves, Journal of Dairy Sciences 87 (2004), 1085-1091.

[15] M.A. Evenson and T. Anderson Jr., Ultramicro analysis for copper, cadmium, and zinc by atomic absorption spectrophotometry and the heated graphite furnace atomizer, Clinical Chemistry 21 (1975), 537-543.

[16] G. Gür, Y. Bayraktar, D. Özer, M. Özdogan and B. Kayan, Determination of hepatic zinc content in chronic liver disease due to hepatitis B virus, Hepato-Gastroenterology 45 (1998), 472-476.

[17] R.G. Treble, T.S. Thompson and H.R. Lynch, Determination of copper, manganese and zinc in human liver, Biometals 11 (1998), 49-53. 


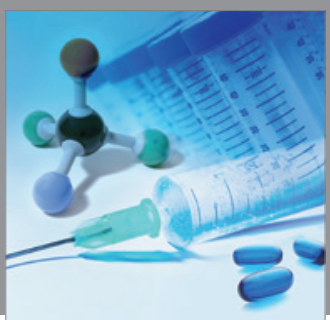

International Journal of

Medicinal Chemistry

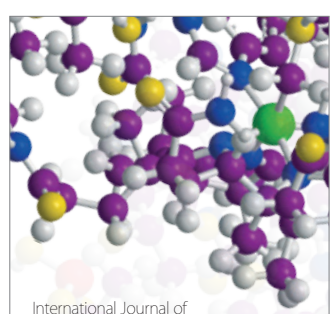

Carbohydrate Chemistry

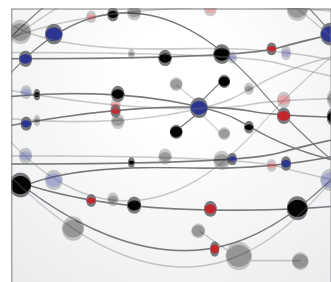

The Scientific World Journal
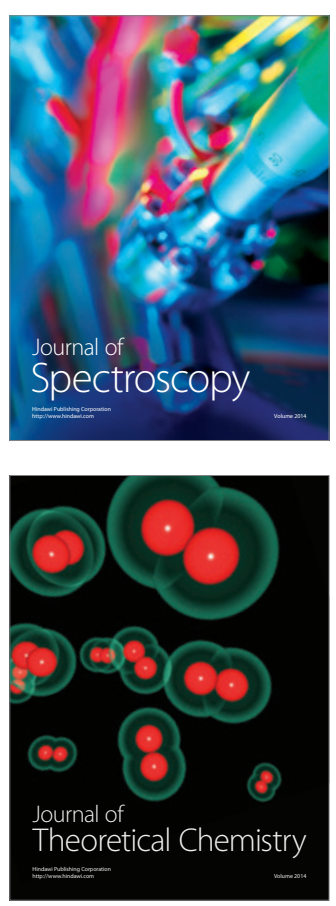
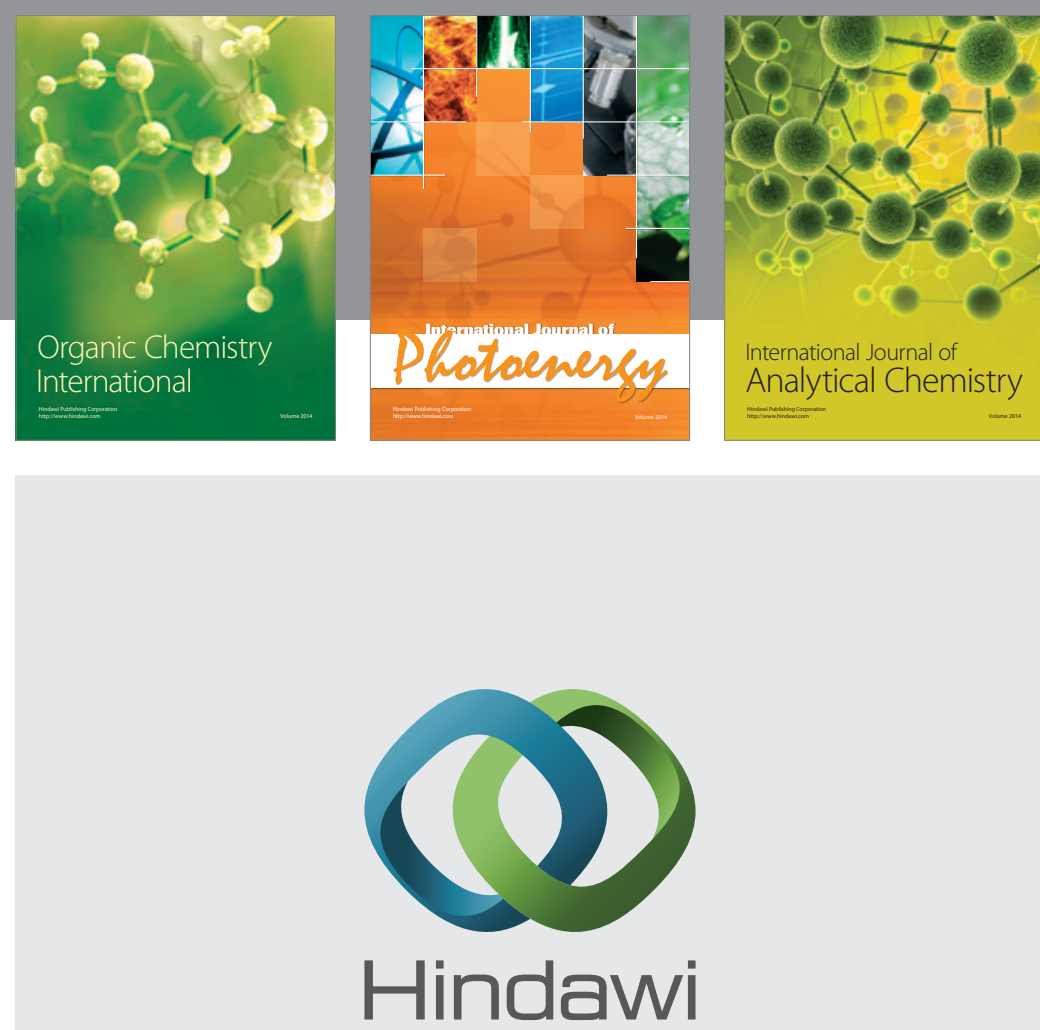

Submit your manuscripts at

http://www.hindawi.com
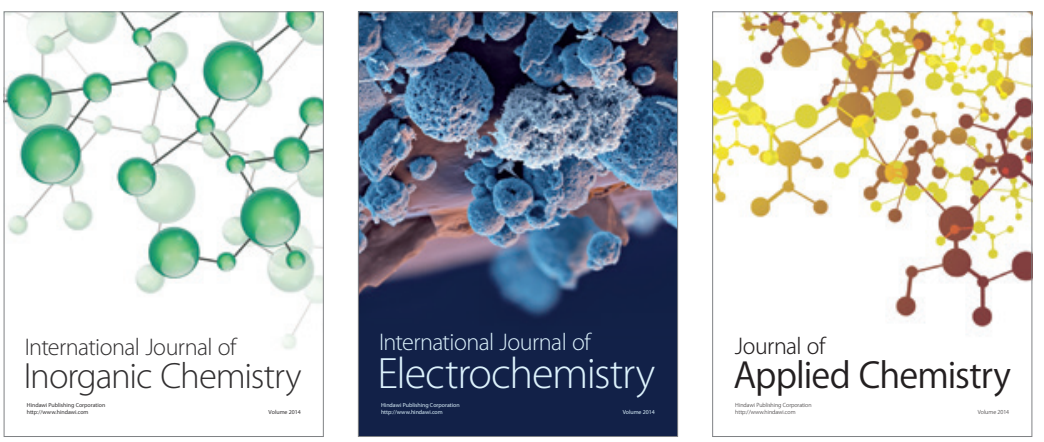

Journal of

Applied Chemistry
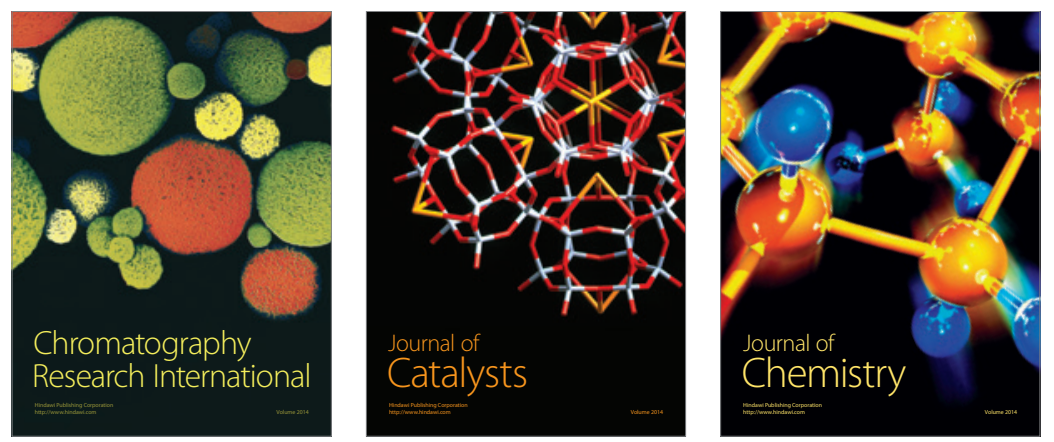
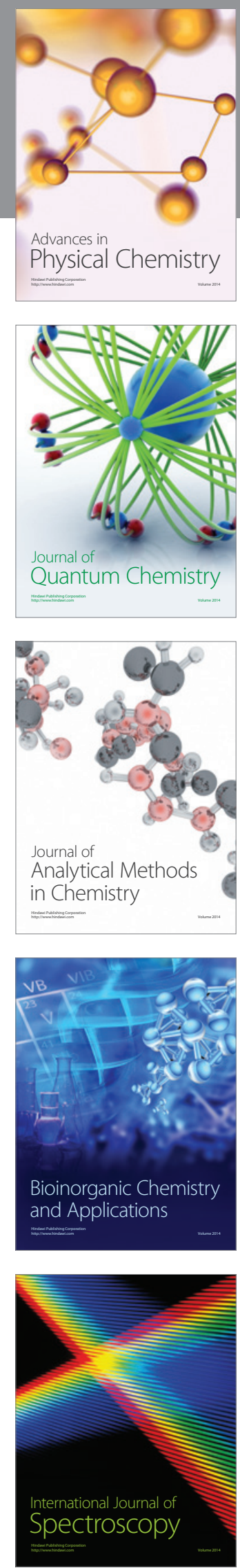